\title{
Optimalisasi Fungsi Ekologis Ruang Terbuka Hijau Publik di Kota Surabaya
}

\author{
Rita Ernawati \\ Program Studi Arsitektur Universitas Islam Negeri Sunan Ampel Surabaya, Indonesia \\ myreeta80@gmail.com
}

\begin{abstract}
Green open spaces is an important element in creating an impressive and qualified city in realizing ecological city in order of ecological city realization. The government policy related to the $30 \%$ proportion provision constitute the minimum size in an effort to ensure an urban development balance. The city of Surabaya has a very strong commitment in the developing public green spaces, especially in the physical and management. Although the green spaces development achievements in the city of Surabaya in general has been quite good, but it needs further study on the optimization of green spaces ecological functions. With a descriptive quantitative method, this study aim to assessing public green space in the city of Surabaya based on dominance aspects of green space and it quality (preservation). Green space ecological functions contribute to the quality improvement of groundwater, flood prevention, air pollution reduction, and supporting in microclimate settings. In general, the analysis showed that the cemetery and garden as a part of the green space in the city of Surabaya has been implementing it ecological function optimally. The public green spaces quality improvement efforts, in order to optimize their ecological function, should be synergized with other programs such as biopore development, channel and rivers management, as well as good waste and private green spaces management by involving all relevant stakeholders. An optimal green space management at each region is a form of sustainable development implementation that can establish the smart, humanist and ecological city of Surabaya.
\end{abstract}

Keywords: optimization, green open spaces, ecological function

Abstrak: Ruang terbuka hijau merupakan elemen penting dalam menciptakan kota yang impresif dan berkualitas dalam mewujudkan kota ekologis. Penetapan proporsi 30\% oleh pemerintah merupakan ukuran minimal untuk menjamin keseimbangan pembangunan kota. Kota Surabaya memiliki komitmen penembangan RTH publik yang sangat kuat dalam pembangunan fisik dan pengelolaan RTH. Meskipun secara umum capaian pembangunan RTH di Kota Surabaya sudah tergolong baik, namun perlu dikaji optimalisasi fungsi ekologis $\mathrm{RTH}$. Dengan metode kuantitatif diskriptif, kajian ini menilai RTH publik di Kota Surabaya berdasarkan aspek dominasi ruang hijau dan kualitas (pemeliharaan). Fungsi ekologis RTH memberi kontribusi dalam peningkatan kualitas air tanah, mencegah terjadinya banjir, mengurangi polusi udara, dan pendukung dalam pengaturan iklim mikro. Hasil analisis menunjukkan bahwa secara umum kondisi RTH makam dan taman di Kota Surabaya sudah optimal dalam melaksanakan fungsi ekologis. Upaya peningkatan kualitas RTH publik untuk mengoptimalkan fungsi ekologis harus disinergikan dengan program lain seperti pengembangan biopori, pengelolan, saluran dan sungai, pengelolaan sampah dan pengelolaan RTH privat secara baik dengan melibatkan seluruh stakeholder pembangunan. Melalui pengelolaan RTH yang optimal disetiap wilayah yang merupakan implementasi pembangunan berkelanjutan mampu menciptakan Kota Surabaya yang cerdas, manusiawi dan ekologis.

Kata Kunci: optimalisasi, ruang terbuka hijau, fungsi ekologis

\section{Pendahuluan}

Menurut data WHO tahun 2008 lebih dari 50\% penduduk dunia tinggal di perkotaan, dan pada tahun 2050 diprediksi mencapai 70\%. Badan Pusat
Stastistik memprediksikan pada tahun 2025 sebanyak $60 \%$ penduduk Indonesia tinggal di kota, angka tersebut menunjukkan peningkatan sekitar $10 \%$ dalam kurun waktu 15 tahun. Kondisi tersebut 
berdampak pada kota yang semakin padat yang mengakibatkan semakin berkurangnya lahan terbuka hijau. Undang-undang Penataan Ruang No. 26 tahun 2007 Pasal 29 menetapkan bahwa kota harus menyediakan $20 \%$ dari luasnya sebagai Ruang Terbuka Hijau (RTH) publik yang dikelola dan disediakan pemerintah serta minimal $10 \%$ disediakan oleh pihak di swasta dan masyarakat. Secara keseluruhan kota minimal harus menyediakan 30\% dari luas kota yang khusus difungsikan sebagai RTH.

Ruang terbuka hijau merupakan elemen penting dalam menciptakan kota yang impresif dan berkualitas dalam mewujudkan kota ekologis. Penetapan proporsi $30 \%$ oleh pemerintah merupakan ukuran minimal untuk menjamin keseimbangan ekosistem kota, baik keseimbangan sistem hidrologi, iklim mikro, maupun sistem ekologis lain yang dapat meningkatkan ketersediaan udara bersih yang diperlukan masyarakat, sekaligus dapat meningkatkan nilai estetika kota. Perkembangan kota yang disertai alih fungsi lahan, telah menimbulkan kerusakan lingkungan yang dapat menurunkan daya dukung lahan dalam menopang kehidupan perkotaan, sehingga perlu dilakukan upaya untuk menjaga dan meningkatkan kualitas lingkungan melalui penyediaan ruang terbuka hijau yang memadai (Silas, dkk., 2014).

Kota Surabaya sejak tahun 2002 telah melakukan serangkaian program pengembangan RTH secara masif. Salah satu upaya ekstrim yang dilakukan adalah revitalisasi lahan milik pemerintah kota yang dialihfungsikan menjadi SPBU untuk dikembalikan fungsinya menjadi RTH. Pemerintah kota juga mengembangkan taman kota tematik, pembangunan hutan kota, pengembangan kawasan konservasi mangrove, RTH kampung, dll (Bappeko, 2012).

Ruang terbuka hijau di Kota Surabaya tidak hanya berfungsi meningkatkan kualitas lingkungan namun juga memiliki fungsi sosial dan ekonomis. Diantara fungsi-fungsi tersebut optimalisasi fungsi ekologis yang harus mendapatkan perhatian lebih karena kondisi fisik Kota Surabaya yang rentan terhadap berbagai kerusakan dan bencana. Beberapa RTH di Kota Surabaya menunjukkan kurang optimalnya fungsi tersebut juka dilihat dari proporsi ruang hijau dan kualitasnya. Makalah ini bertujuan menjabarkan hasil analisis kondisi RTH berdasarkan optimalisasi fungsi ekologis pada RTH makam, lapangan dan stadion, bozem dan waduk, sempadan sungai, sempadan jalan dan taman aktif.

\section{Tinjauan Konseptual}

\subsection{Konsep Garden City dan Pengembangan Ruang Terbuka Hijau}

Pada masa revolusi industri kota-kota di dunia mengalami degradasi kualitas lingkungan yang parah karena tingkat pencamaran lingkungan yang tinggi. Selain itu juga terjadi kesenjangan yang tajam antara kota dan desa. Kondisi tersebut mendorong para perencana kota pada abad ke 20-an mengembangkan konsep kota ideal. Di Inggris, Sir Ebenezer Howard merupakan salah satu tokoh yang mencoba mengembangkan sebuah konsep kota baru. Dalam bukunya yang berjudul Garden Cities of Tomorrow pada tahun 1902, Ebenezer Howard menawarkan visi kota membebaskan kota dari area kumuh dengan mensinergikan kelebihan kota dan desa "Town and Country must be married, and out of this joyous union will spring a new hope, a new life, a new civilization" (Corovic, 2009).

Konsep garden city menekankan pantingnya aspek lingkungan dan manusia dalam merencanakan kota. Malalui kampanye di berbagai institusi, konsep tersebut diterima oleh pemerintah Inggris untuk diwujudkan. Kota pertama yang dikembangkan dengan konsep garden city adalah Letchworth di sekitar London.

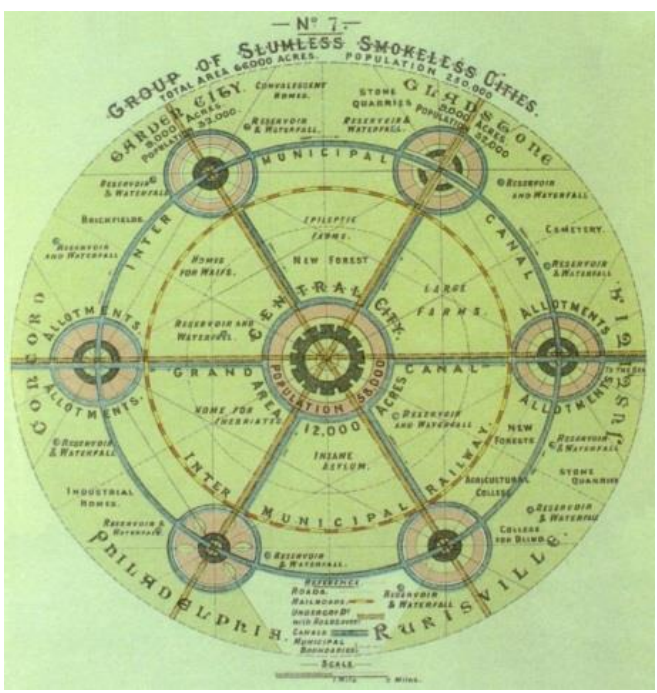

Gambar 1. Konsep Garden City

(Sumber: www.irb.co.uk dalam Silas, 2009)

Implementasi tersebut memberikan inspirasi pengembangan di kota-kota lain, dengan merancang peletakan pusat lingkungan di kota satelit dan menerapkan prinsip desain humanis. Di Indonesia perencanaan kota pada masa Pemerintahan Belanda juga menerapkan konsep garden city, dengan adanya alun-alun dan taman-taman. Konsep tersebut juga menjadi dasar pengembangan RTH kota. 


\subsection{Konsep Ruang Terbuka Hijau}

Ruang terbuka hijau merupakan eleman penting dalam pengembangan pembangunan berkelanjutan. RTH merupakan konsep dalam multidisiplin ilmu, sehingga definisinya dipahami dalam beragam perspektif (Atiqul Haq, 2011; Bilgili, 2012). Menurut Bilgli, 2012) RTH kota didefinisikan sebagai pemanfaaran lahan dan permukaan lahan yang ditutupi oleh eleman tanaman alami dan yang ditanam manusia.

Kementerian Lingkungan Hidup (2008) dalam buku "Kota Ekologis" mendefinisikan ruang terbuka hijau sebagai ruang atau area terbuka di dalam kota yang ditumbuhi tanaman hijau, baik berupa pohon besar, semak, perdu, maupun rumput. Selain menciptakan keindahan bagi kota ruang terbuka hikau juga memiliki fungsi utama sebagai penyeimbang lingungan. Berdasarkan Undang-Undang Nomor 26 Tahun 2007 tentang Penataan Ruang disebutkan bahwa pengertian RTH adalah area memanjang/jalur dan atau mengelompok, yang penggunaannya lebih bersifat terbuka, tempat tumbuh tanaman, baik yang tumbuh tanaman secara alamiah maupun yang sengaja ditanam. Ruang Terbuka Hijau Kawasan Perkotaan (RTHKP) berdasarkan Peraturan Menteri Dalam Negeri Nomor 1 Tahun 2007 tentang Ruang Terbuka Hijau Kawasan Perkotaan adalah bagian dari ruang terbuka suatu kawasan perkotaan yang diisi oleh tumbuhan dan tanaman guna mendukung manfaat ekologi, sosial, budaya, ekonomi, dan estetika.

\subsection{Manfaat dan Fungsi Ruang Terbuka Hijau}

Menurut Atiqul Haq (2011) secara umum terdapat tiga manfaat RTH yaitu manfaat secara lingkungan, sosial dan ekonomis. Manfaat secara lingkungan dijabarkan dalam tiga hal yaitu ekologis (memelihara stabilitas iklim), mengontrol polusi dan konservasi keragaman alam. Barton (2009) merumuskan adanya manfaat terhadap kesehatan mental disamping manfaat sosial dan fisik pengembangan RTH. Dalam konteks pengembangan RTH pada kawasan perkotaan di Indonesia Silas, dkk (2014) menyebutkan manfaat RTH sebagai berikut:

a. Sarana untuk mencerminkan identitas (citra) daerah

b. Sarana penelitian, pendidikan, dan penyuluhan

c. Sarana rekreasi aktif dan rekreasi pasif, serta interaksi sosial

d. Meningkatkan nilai ekonomis lahan perkotaan e. Menumbuhkan rasa bangga dan meningkatkan prestise daerah

f. Sarana aktivitas sosial bagi anak-anak, remaja, dewasa dan manula

g. Sarana ruang evakuasi untuk keadaan darurat

h. Memperbaiki iklim mikro, dan

i. Meningkatkan cadangan oksigen di perkotaan.

Dalam rencana tata ruang kedudukan $\mathrm{RTH}$ merupakan ruang terbuka publik yang direncanakan pada suatu kawasan, yang tersusun atas RTH dan ruang terbuka non-hijau. Ruang terbuka hijau, memiliki fungsi dan peran khusus pada masingmasing kawasan yang ada pada setiap perencanaan tata ruang kabupaten/kota, yang direncanakan dalam bentuk penataan tumbuhan, tanaman, dan vegetasi, agar dapat berperan dalam mendukung fungsi ekologis, sosial budaya, dan arsitektural, sehingga dapat memberi manfaat optimal bagi ekonomi dan kesejahteraan bagi masyarakat, sebagai berikut.

a. Fungsi ekologis; RTH diharapkan dapat memberi kontribusi dalam peningkatan kualitas air tanah, mencegah terjadinya banjir, mengurangi polusi udara, dan pendukung dalam pengaturan iklim mikro

b. Fungsi sosial budaya; RTH diharapkan dapat berperan terciptanya ruang untuk interaksi sosial, sarana rekreasi, dan sebagai penanda (tetengerl landmark) kawasan.

c. Fungsi arsitektural/estetika; RTH diharapkan dapat meningkatkan nilai keindahan dan kenyamanan kawasan, melalui keberadaan taman, dan jalur hijau

d. Fungsi ekonomi; RTH diharapkan dapat berperan sebagai pengembangan sarana wisata hijau perkotaan, sehingga menarik minat masyarakat / wisatawan untuk berkunjung ke suatu kawasan, sehingga secara tidak langsung dapat meningkatkan kegiatan ekonomi

Secara spesifik pengembangan RTH kota turut mendukung capaian Millenium Development Goals (MDG's) Indonesia. Pengembangan RTH termasuk dalam salah satu MDG's yaitu memastikan kelestarian lingkungan hidup, dengan indikatorindikator capaian sebagai berikut:

1) Meningkatnya rasio luas kawasan tertutup pepohonan berdasarkan hasil pemotretan citra satelit dan survey foto udara terhadap luas daratan. 
2) Berkurangnya jumlah emisi karbondioksida (CO2) yaitu 26\% pada tahun 2020.

3) Mengurangi jumlah konsumsi bahan perusak ozon (BPO) dalam metric ton yaitu 0 CFCs.

4) Pembatasan proporsi tangkapan ikan yang berada dalam batasan biologis yang aman.

5) Meningkatnya rasio luas kawasan lindung untuk menjaga kelestarian keanekaragaman hayati terhadap total luas kawasan hutan.

6) Meningkatnya Rasio kawasan lindung perairan terhadap total luas perairan territorial.

Penjabaran diatas menunjukkan bahwa RTH memiliki peran penting tidak hanya bagi manusia, namun juga dalam lingkup lebih luas (wilayah). Untuk mengoptimalkan manfaat dan fungsi RTH membutuhkan peran serta seluruh stakeholder dalam pengembangannya.

\subsection{Tipologi Ruang Terbuka Hijau}

Tipologi RTH dapat dipahami dari beberapa kriteria seperti berdasarkan ukuran, kepemilikan, fungsi, lokasi, dll (Byrne and Sipe, 2010 dalam Bilgili, 2012). Dalam konteks RTH kota pengelompokkan didasarkan pada karakteristik spasial, tujuan atau pemanfaatan dan kepemilikan. Menurut Bilgili (2012) RTH publik terdiri dari taman kota (park), ruang hijau alami dan ruang hijau konservasi (natural \& protected green space), dan sungai, aliran air dan danau (river, stream, lake). Sedangkan, RTH privat terdiri dari taman pribadi (private garden), tanah institusi (institutional land). Gambar berikut menunjukkan tipologi RTH menurut Bilgili.

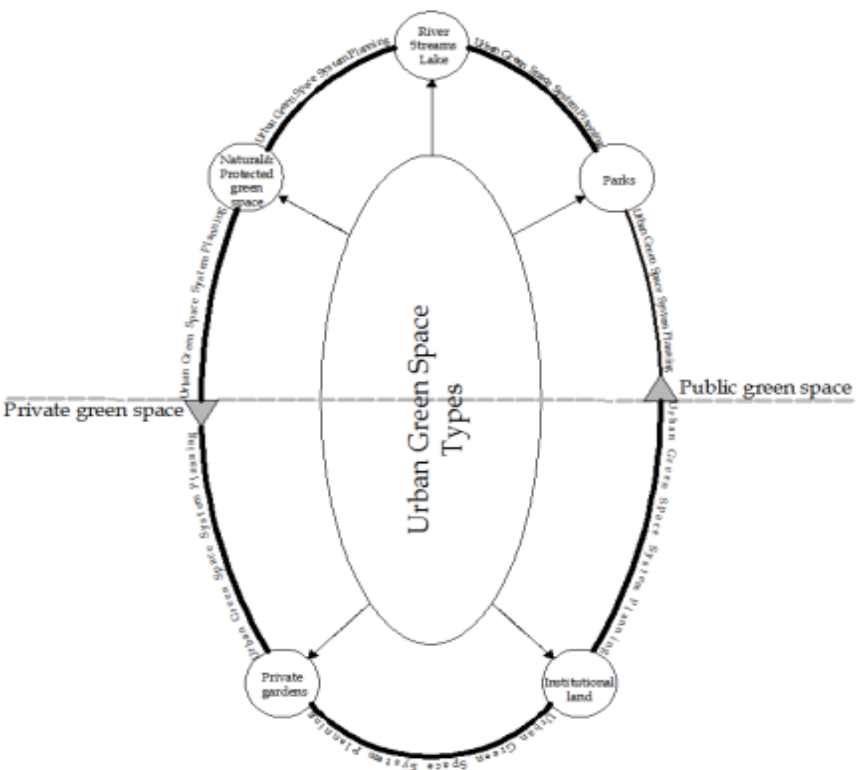

Gambar 2. Tipologi Ruang Terbuka Hijau Kota (Sumber: Bilgili, 2012)
Di Indonesia tipologi RTH kota diatur dalam Permen PU Nomor 5/PRT/M/2008 tentang Pedoman Penyediaan dan Pemanfaatan Ruang Terbuka Hijau di Kawasan Perkotaan, tipologi RTH dibedakan berdasarkan fisik, fungsi, struktur dan kepemilikan. Secara fisik RTH dapat dibedakan menjadi RTH alami berupa habitat liar alami, kawasan lindung dan tamantaman nasional serta RTH non alami atau binaan seperti taman, lapangan olahraga, pemakaman atau jalur-jaur hijau jalan.

Dilihat dari fungsi RTH dapat berfungsi ekologis, sosial budaya, estetika, dan ekonomi. Secara struktur ruang, RTH dapat mengikuti pola ekologis (mengelompok, memanjang, tersebar), maupun pola planologis yang mengikuti hirarki dan struktur ruang perkotaan. Dari segi kepemilikan, RTH dibedakan ke dalam RTH publik dan RTH privat. Pembagian jenisjenis RTH publik dan RTH privat. Berikut ini diagram yang menunjukkan tipologi RTH dan penjabarannya.

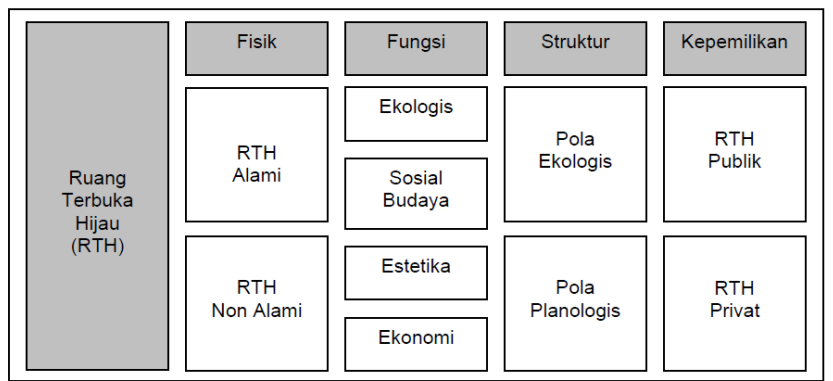

Gambar 3 Diagram Tipologi Ruang Terbuka Hijau (Sumber: Permen PU No. 05/PRT/M/2008)

\section{Metode Kajian}

Makalah ini merupakan bagian dari hasil penelitian yang dilakukan peneliti bersama tim peneliti Laboratorium Perumahan Permukiman ITS Surabaya pada tahun 2012 dengan judul Kajian Optimalisasi Pemanfaatan Ruang Terbuka Hijau Publik di Kota Surabaya. Makalah ini menyajikan hasil analisis fungsi ekologis di Kota Surabaya dengan menilai kondisi RTH Metode yang diterapkan dalam kajian ini adalah kuantitatif diskriptif. Data yang dibutuhkan dalam kajian ini terdiri dari data primer Data primer diperoleh dari data Pemerintah Kota Surabaya terkait pengembangan RTH publik baik berupa hasil kajian maupun data statistik. Data primer diperoleh melalui survei lapangan dengan melakukan observasi kondisi RTH publik. Data primer lebih difokuskan pada sintesa optimalisasi fungsi RTH baik fungsi ekologi, sosial, maupun ekonomi.

Penilaian optimalisasi fungsi ekologis RTH didasarkan pada variabel dominasi ruang hijau yang disyaratkan pada suatu RTH menurut Permen PU No 5 Tahun 2008 tentang Pedoman Penyediaan dan 
Pemanfaatan Ruang Terbuka Hijau di Kawasan Perkotaan. Selain itu juga diidentifikasi kualitas RTH dengan mengobservasi tingkat keterawatan dan perawatan yang dilakukan. Berikut ini kriteria prosentase ruang hijau pada $\mathrm{RTH}$.

Tabel 1.Prosentase Minimal Ruang Hijau pada RTH

\begin{tabular}{|l|c|}
\hline \multicolumn{1}{|c|}{ Jenis RTH } & $\%$ Minimal Ruang Hijau \\
\hline Taman & $80-90 \%$ \\
\hline Hutan Kota & $90 \%$ \\
\hline Sempadan Pantai & $90-100 \%$ \\
\hline Makam & $70-80 \%$ \\
\hline
\end{tabular}

Sumber: Permen PU No 5 Tahun 2008

Dengan mempertimbangkan persyaratan minimal diatas, dalam kajian ini dirumuskan 4 (empat) ketegori kondisi RTH yaitu:

a. Kondisi RTH sangat optimal; jika dominasi ruang hijau lebih dari $80 \%$

b. Kondisi RTH optimal; jika dominasi ruang hijau antara $50 \%$ s/d $80 \%$

c. Kondisi RTH kurang optimal; jika dominasi ruang hijau antara $25 \% \mathrm{~s} / \mathrm{d} 50 \%$

d. Kondisi RTH tidak optimal; jika dominasi ruang hijau kurang dari $25 \%$

Untuk mengidentifikasi tingkat keterawatan RTH, dalam kajian ini dirumuskan 3 kategori yaitu:

a. Kondisi RTH terawat; jika kondisi bersih karena secara rutin dirawat

b. Kondisi RTH kurang terawat; jika kondisi kurang bersih karena perawatan dilakukan secara temporal

c. Kondisi RTH tidak terawat; jika kondisi kotor karena tidak ada perawatan

Identifikasi tingkat keterawatan RTH didasarkan pada tingkat kebersihan dan frekuensi kegiatan perawatan (maintenance). Identifikasi ini penting untuk menjaga keberlanjutan RTH yang sudah ada agar mampu bertahan bahkan meningkat secara kualitas. Analisis terhadap optimalisasi fungsi ekologis RTH publik didasarkan pada kedua aspek diatas.

\section{Pembahasan}

\subsection{Kebijakan Pengembangan RTH Kota Surabaya}

Salah satu misi pembangunan Kota Surabaya menurut RTRW 2012-2032 adalah meningkatkan kualitas penataan ruang kota dan infrastruktur kota yang menjamin aksesibilitas publik berwawasan lingkungan dan nyaman. Penetapan misi tersebut merupakan suatu upaya untuk mewujudkan pengembangan kota ekologis yang salah satu indikatornya adalah penyediaan RTH. Implementasi misi tersebut dijabarkan dalam bentuk kebijakan dan program di bidang $\mathrm{RTH}$, melalui pengembangan $\mathrm{RTH}$ Privat maupun RTH Publik. Pengembangan RTH Privat diadakan melalui langkah-langkah:

a. penyediaan lahan pekarangan pada bangunan rumah, fasilitas umum / sosial dan komersial berupa tanah yang dapat ditanami minimum seluas $10 \%$ dari luas persil,

b. Peningkatan luasan dan pengunaan RTH berupa taman atap bangunan (roof garden), dan

c. Peningkatan penyediaan RTH melalui media pot dan tanaman rambat.

Kebijakan pengelolaan RTH diatur Peraturan Daerah Kota Surabaya No 7 Tahun 2002. Kebijakan tersebut telah diimplementasikan dalam serangkaian langkah, pengembangan RTH yaitu:

1) Mengembalikan fungsi lahan peruntukan RTH yang disalahgunakan untuk fungsi lain atau fungsi komersial (misalnya menggusur SPBU yang berada di lahan RTH / jalur hijau).

2) Meningkatkan kesadaran dan komitmen pihak pengembang swasta dalam penyediaan RTH baik kawasan perumahan, kawasan perdagangan maupun kawasan industri.

3) Pengembangan kawasan Pamurbaya (Pantai Timur Surabaya) menjadi kawasan konservasi mangrove seluas $2.540 \mathrm{Ha}$.

4) Pembangunan taman di berbagai sudut kota dengan berbagai tema dan ragam fungsi. Taman kota didesain agar bisa dimanfaatkan oleh seluruh lapisan warga Surabaya secara gratis.

5) Perbaikan dan penghijauan kampung-kampung lama menjadi kampung layak huni, hijau, sehat dan manusiawi dengan berbagai program dan kegiatan, untuk membangkitkan kesadaran warga akan pentingnya kondisi lingkungan dalam memperbaiki kualitas hidup warga.

6) Pemanfaatan lahan-lahan tidak produktif menjadi kawasan RTH (hutan dan taman), misalnya lahan bekas TPA yang sudah berhenti operasionalnya dan telah ada perencanaan untuk memanfaatkannya menjadi hutan dan taman kota sekaligus tempat rekreasi yang murah bagi warga kota.

7) Pengembangan kawasan urban farming dan urban biodiversity di beberapa wilayah pinggiran Kota Surabaya.

Ruang Terbuka Hijau publik Kota Surabaya dikembangkan dengan tujuan menciptakan kota 
berwawasan lingkungan sebagai penyangga kebutuhan air kota, kontrol iklim kota, fungsi sosial, fungsi estetika, penyedia kebutuhan oksigen, dan menjamin kenyamanan masyarakat kota. Target luasan minimal RTH Publik Kota Surabaya ditetapkan sebesar $20 \%$ terhadap luas kota. Ruang Terbuka Hijau publik Kota Surabaya terdiri dari RTH jalur jalan, taman pasif dan persimpangan jalan, monumen dan gerbang kota, taman aktif, lapangan olahraga dan makam, hutan kota dan kebun bibit, RTH pengaman jalur KA, SUTT, sungai, dan buffer zone (Bappeko, 2012).

\subsection{Identifikasi Pengembangan RTH Kota Surabaya}

Data Bappeko tahun 2012 menunjukkan bahwa luas RTH Publik Kota Surabaya hampir mencapai target $30 \%$. Capaian tersebut semakin meningkat dengan pengembangan RTH yang masif baik secara kualitas maupun kuantitas. Fungsi ekologis RTH pada suatu wilayah diharapkan dapat memberi kontribusi dalam peningkatan kualitas air tanah, mencegah terjadinya banjir, mengurangi polusi udara, dan pendukung dalam pengaturan iklim mikro. Untuk mengakomodasi fungsi ekologis tersebut RTH harus memiliki proporsi area yang ditumbuhi tanaman (hijau) dengan komposisi yang optimal. Hal tersebut karena tanamam memegang peran penting dalam penyerapan polusi udara, penyerapan air hujan, yang berpengaruh pada stabilitas iklim.

Hasil kajian Bappeko 2012 terhadap dominasi ruang hijau dan kualitas RTH publik dilakukan pada RTH makam, lapangan dan stadion, bozem dan waduk, sempadan sungai, sempadan jalan dan taman aktif. Analisis dilakukan dalam satuan jumlah unit RTH. Tabel berikut menunjukkan rekapitulasi hasil analisis kondisi RTH publik berdasarkan dominasi area hijau pada masing-masing jenis RTH.

Tabel 2. Kondisi RTH Publik berdasarkan Dominasi Area Hijau

\begin{tabular}{|l|l|l|l|l|}
\hline Jenis RTH & $\begin{array}{c}\text { Sangat } \\
\text { Optimal }\end{array}$ & Optimal & $\begin{array}{c}\text { Kurang } \\
\text { Optimal }\end{array}$ & $\begin{array}{c}\text { Tidak } \\
\text { Optimal }\end{array}$ \\
\hline Makam & 13.25 & 40.96 & 31.33 & 14.46 \\
\hline Lapangan\&Stadion & 10.98 & 12.20 & 32.93 & 43.90 \\
\hline Bozem\&waduk & 8.70 & 43.48 & 26.09 & 21.74 \\
\hline Sempadan Sungai & 36.84 & 31.58 & 26.32 & 5.26 \\
\hline SempadanJalan & 18.98 & 36.79 & 41.77 & 27.46 \\
\hline Taman Aktif & 8.33 & 58.33 & 31.94 & 1.39 \\
\hline Kondisi Rata-rata & $\mathbf{1 6 . 1 8}$ & $\mathbf{3 7 . 2 2}$ & $\mathbf{3 1 . 7 3}$ & $\mathbf{1 9 . 0 4}$ \\
\hline
\end{tabular}

Sumber: Bappeko Kota Surabaya 2012

Secara umum kondisi RTH publik di Kota Surabaya dari aspek dominasi area hijau sudah cukup baik namun masih perlu ditingkatkan untuk mengoptimalkan fungsi ekologis. Tabel 2 menunjukkan bahwa rata-rata kondisi optimal dominasi ruang hijau RTH kurang dari 50\% RTH. Terdapat $31.73 \%$ RTH dengan dominasi ruang hijau yang tergolong kurang optimal, dan hanya $19.04 \%$ tergolong tidak optimal. Kondisi yang tidak optimal ditemukan pada RTH sempada jalan dan bozem \& waduk. Hal tersebut dikarenakan sempadan jalan di Kota Surabaya lebih difungsikan sebagai trotoar, sedangkan bozem \& waduk difungsikan sebagai penyimpan cadangan air (lebih dominan elemen air).

Selain penilaian terhadap dominasi ruang hijau, makalah ini juga menjabarkan hasil penilaian terhadap pengelolaan / perawatan RTH yang juga merupakan aspek penting untuk mengoptimalkan fungsi ekologis. Kondisi RTH yang terawat akan mampu memaksimalkan penyerapan polusi udara dan penyerapan air. Berikut ini tabel kondisi RTH publik berdasarkan tingkat keterawatan di Kota Surabaya.

Tabel 3. Kondisi RTH Publik berdasarkan Tingkat Keterawatan

\begin{tabular}{|l|c|c|c|}
\hline \multicolumn{1}{|c|}{ Jenis RTH } & Terawat & $\begin{array}{c}\text { Kurang } \\
\text { Terawat }\end{array}$ & $\begin{array}{c}\text { Tidak } \\
\text { Terawat }\end{array}$ \\
\hline RTH Makam & 13.25 & 61.45 & 25.30 \\
\hline RTH Lapangan\&Stadion & 12.20 & 65.85 & 21.95 \\
\hline RTH Bozem\&waduk & 0.00 & 47.83 & 52.17 \\
\hline RTH Sempadan Sungai & 15.79 & 68.42 & 15.79 \\
\hline RTH SempadanJalan & 28.78 & 70.67 & 25.55 \\
\hline RTH Taman Aktif & 66.67 & 27.78 & 5.56 \\
\hline Kondisi Rata-rata & $\mathbf{2 2 . 7 8}$ & $\mathbf{5 7 . 0 0}$ & $\mathbf{2 4 . 3 9}$ \\
\hline
\end{tabular}

Sumber: Bappeko Kota Surabaya 2012

Tabel diatas menunjukkan bahwa secara umum perawatan RTH publik di Kota Surabaya masih perlu ditingkatkan karena hanya $22.78 \%$ yang dirawat secara rutin. Perawatan RTH publik yang sudah cukup optimal dilaksanakan adalah pada taman aktif. Untuk RTH publik lain prosentase perawatan masih dibawah $30 \%$. Kajian sebelumnya menggunakan satuan jumlah unit RTH, dimana variabel luas lahan diabaikan sehingga hasil analisis terindikasi kurang akurat.

Agar analisis optimalisasi fungsi ekologis lebih akurat, analisis lebih lanjut dilakukan peneliti, dengan menggunakan satuan unit luas RTH. Hasil secara umum menunjukkan defisiasi prosentase pada masing-maisng kondisi dan tipe RTH. Secara lebih detail makalah ini menjabarkan kondisi dominasi ruang hijau dan pengelolaan pada RTH makam dan taman aktif. 


\subsection{Analisis Optimalisasi Fungsi Ekologis pada RTH Makam}

RTH makam yang ada di Kota Surabaya dikelompokkan menjadi 2 (dua) yaitu; makam BTKD dan makam dikelola oleh DKP. Karakteristik kondisi makam pada umumnya terdiri dari 2 (dua) jenis yaitu makam lama dengan dominasi pusara yang dibangun (diperkeras) dan makam baru dengan pusara tidak dibangun (hanya terdapat nisan). Luas makam hingga tahun 2012 adalah $\quad 2,286,715.51 \mathrm{~m} 2$ atau sekitar $4.4 \%$ luas Kota Surabaya. Analisis optimalisasi fungsi ekologis RTH makam berdasarkan dominasi ruang hijau dan tingkat perawatan dijabarkan pada grafik berikut.

Grafik 1.Kondisi RTH Makam berdasarkan Dominasi Ruang Hijau

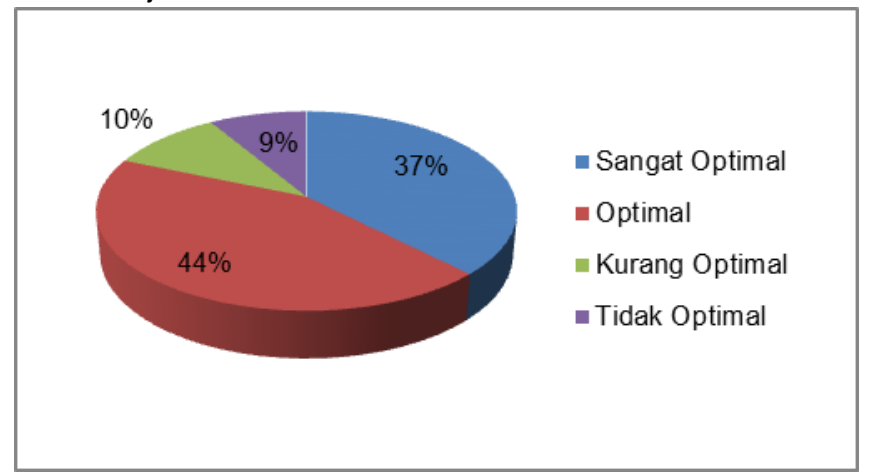

Sumber: Hasil Analisis, 2015

Grafik diatas menunjukkan bahwa kondisi RTH makam di Kota Surabaya sangat optimal dalam melaksanakan fungsi ekologis. Prosentase dominasi ruang hijau pada $\mathrm{RTH}$ makam pada masing-masing kategori adalah 37\% tergolong sangat optimal, $44 \%$ optimal, $10 \%$ kurang optimal dan masih terdapat $9 \%$ tergolong tidak optimal. Kondisi tidak optimal biasa ditemukan pada makam-makam lama yang karena budaya masyarakat membangun pusara (perkerasan) diatas makam. Gambar 3 menunjukkan ilustrasi kondisi makam yang tergolong mampu melaksanakan fungsi ekologis secara optimal.

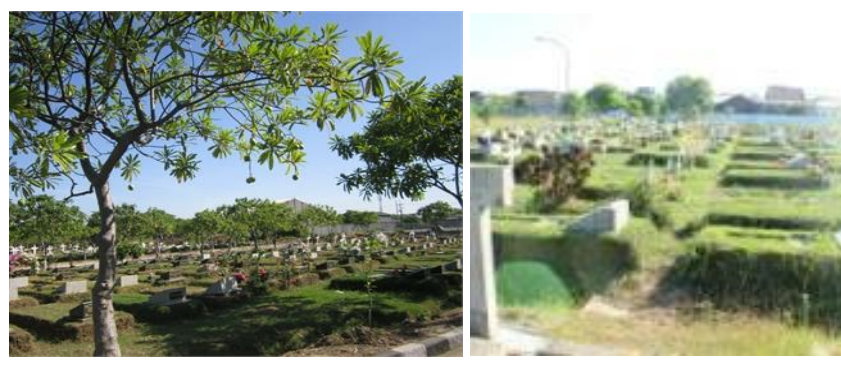

Gambar 4. Kondisi RTH Makam dengan Fungsi Ekologis Optimal (Sumber: Bappeko Kota Surabaya, 2012)
Analisis terhadap kualitas RTH makam di Kota Surabaya didasarkan pada pengelolaan dan pemeliharaan. Dari total luas lahan RTH makam $229.53 \mathrm{Ha}$, terdapat $100.45 \mathrm{Ha}$ makam dengan kondisi baik, 105.13 Ha tegolong kualitas sedang dan masih terdapat $23.93 \mathrm{Ha}$ dengan kualitas kurang baik. Grafik 2 menunjukkan prosentase kualitas RTH makam di Kota Surabaya.

Grafik 2 Kondisi RTH Makam berdasarkan Keterawatan

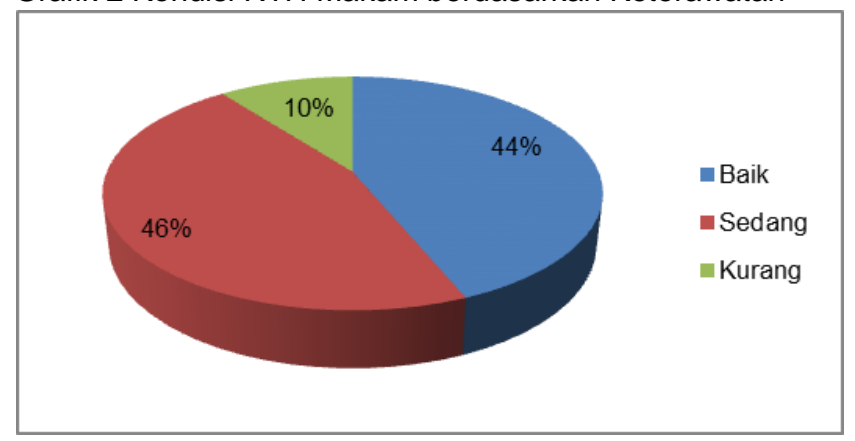

(Sumber: Hasil Analisis, 2012)

Kualitas RTH makam di Kota Surabaya secara umum tergolong baik; dimana $44 \%$ dalam kategori baik, $46 \%$ tergolong sedang dan masih terdapat $10 \%$ makam dengan kualitas kurang baik. Gambar 4 menunjukkan ilustrasi kondisi makam yang tergolong mampu melaksanakan fungsi ekologis dengan cukup optimal.

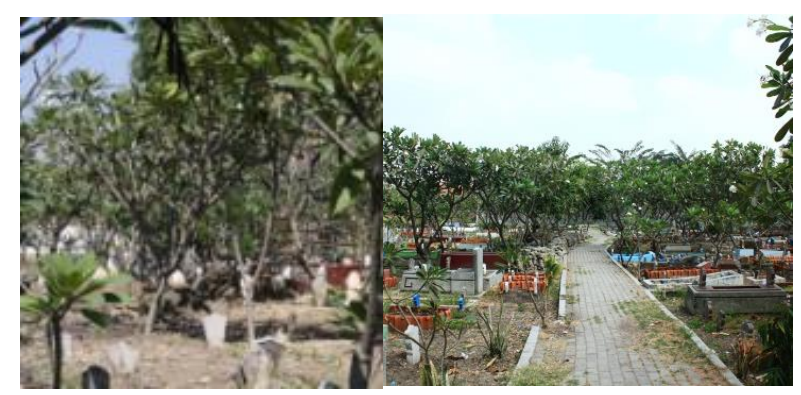

Gambar 5. Kondisi RTH Makam dengan Fungsi Ekologis Cukup Optimal

(Sumber: Bappeko Kota Surabaya, 2012)

\subsection{Analisis Optimalisasi Fungsi Ekologis RTH Taman}

HIngga tahun 2012, di Kota Surabaya telah dikembangkan 72 taman aktif skala kota dengan berbagai konsep dan tema. Taman aktif tersebar di seluruh wilayah Surabaya, dengan rincian di Surabaya Pusat terdapat sebanyak 17 taman, Surabaya Utara sebanyak 7 taman, Surabaya Selatan sebanyak 19 taman, Surabaya Timur sebanyak 21 taman dan Surabaya Barat sebanyak 8 taman. Total luas taman aktif di Kota Surabaya tahun 2012 mencapai $38,68 \mathrm{Ha}$ yang hanya $0.12 \%$ dari total $\mathrm{RTH}$ 
kota. Kondisi RTH taman berdasarkan dominasi ruang hijau dijelaskan pada grafik berikut.

Grafik 3. Kondisi RTH Taman berdasarkan Dominasi Ruang Hijau

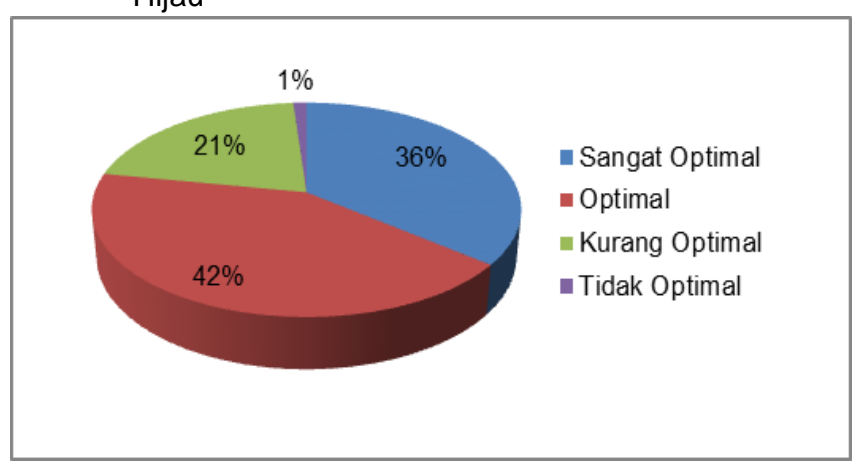

Sumber: Hasil Analisis, 2015

Grafik diatas menunjukkan bahwa kondisi RTH taman di Kota Surabaya sangat optimal dalam melaksanakan fungsi ekologis.Prosentase dominasi ruang hijau pada $\mathrm{RTH}$ taman pada masing-masing kategori adalah $36 \%$ tergolong sangat optimal, $42 \%$ optimal, $21 \%$ kurang optimal dan hanya $1 \%$ tergolong tidak optimal. Kondisi tidak optimal ditemukan di taman BMX tepi Sungai Kalimas. Kondisi kurang optimal dikarenakan taman juga bersifat rekreatif sehingga banyak eleman fisik yang dikembangkan. Gambar 5 menunjukkan ilustrasi kondisi taman yang tergolong mampu melaksanakan fungsi ekologis secara optimal.
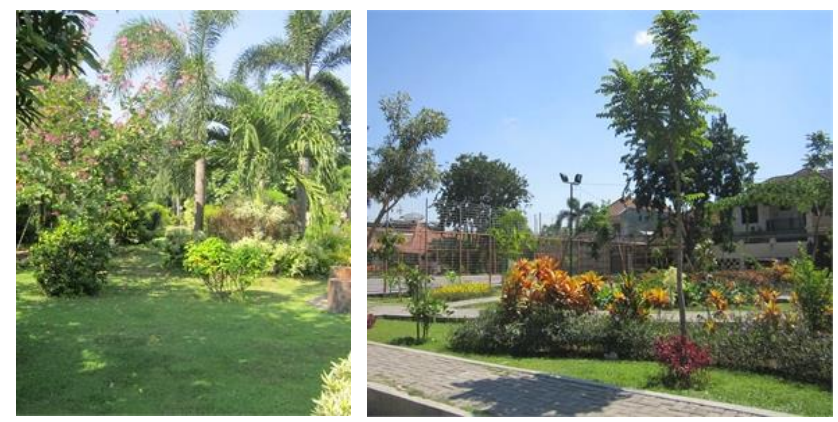

Gambar 6. Kondisi RTH Taman dengan Fungsi Ekologis Optimal

(Sumber: Bappeko Kota Surabaya, 2012)

Analisis terhadap kualitas RTH taman di Kota Surabaya didasarkan pada pengelolaan dan pemeliharaan. Dari total luas lahan RTH makam $38.68 \mathrm{Ha}$, terdapat $30.33 \mathrm{Ha}$ makam dengan kondisi baik, $7.44 \mathrm{Ha}$ tegolong kualitas sedang dan masih terdapat $9.10 \mathrm{Ha}$ dengan kualitas kurang baik. Grafik 4 menunjukkan prosentase kualitas RTH taman di Kota Surabaya.
Grafik 4. Kondisi RTH Taman Aktif berdasarkan Keterawatan

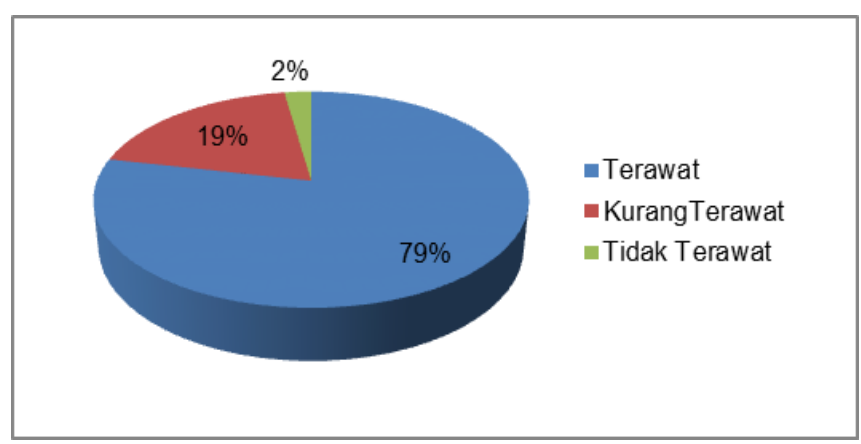

Sumber: Hasil Analisis, 2012

Kualitas RTH taman di Kota Surabaya secara umum tergolong sangat baik; dimana $79 \%$ dalam kategori baik, $19 \%$ tergolong sedang dan hanya terdapat $2 \%$ makam dengan kualitas kurang baik. Gambar 6 menunjukkan ilustrasi kondisi taman yang tergolong mampu melaksanakan fungsi ekologis dengan kurang optimal.

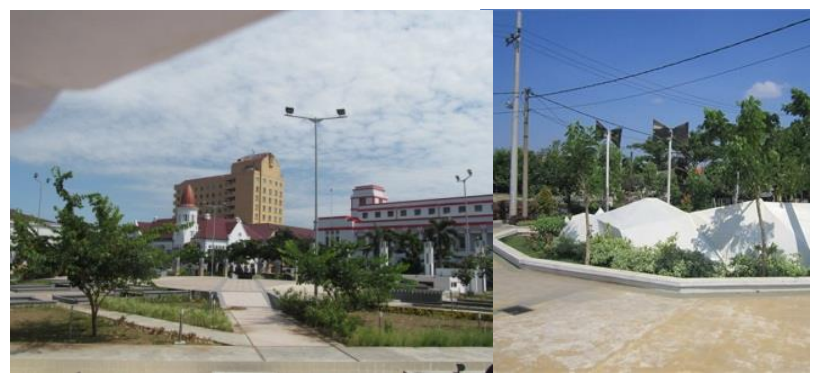

Gambar 6. Kondisi RTH Taman dengan Fungsi Ekologis Kurang Optimal

(Sumber: Bappeko Kota Surabaya, 2012)

\subsection{Optimalisasi Fungsi Ekologis Ruang Terbuka Hijau}

Fungsi ekologis RTH pada suatu wilayah diharapkan dapat memberi kontribusi dalam peningkatan kualitas air tanah, mencegah terjadinya banjir, mengurangi polusi udara, dan pendukung dalam pengaturan iklim mikro. Untuk mengakomodasi fungsi ekologis tersebut RTH harus memiliki proporsi area dengan komposisi optimal. Hal tersebut karena tanamam mem egang peran penting dalam penyerapan polusi udara, penyerapan air hujan, yang berpengaruh pada stabilitas iklim. Peran serta aktif masyarakat dalam pengembangan RTH diharapkan dapat memberi kontribusi signifikan dalam optimalisasi fungsi ekologis, dengan menjaga kelestarian dan ikut meingkatkan kuantitas RTH. dalam setiap proses dan tahapan perencanaan RTH. Keterlibatan seluruh eleman kota (pemerintah, masyarakat, swasta, dII) harus ditingkatkan dalam 
pengembangan RTH. Perawatan RTH publik sangat penting untuk menjamin optimalnya fungsi ekologis pada RTH, agar mampu memberikan kontribusi bagi peningkatan kualitas lingkungan hidup kota.

\section{Kesimpulan}

Berdasarkan analisis optimalisasi fungsi ekologis RTH terhadap dominasi ruang hijau dan pengelolan RTH makam dan taman di Kota Surabaya, dapat dirumuskan beberapa kesimpulan sebagai berikut:

1. Hasil analisis menunjukkan bahwa secara umum kondisi RTH makam dan taman di Kota Surabaya sudah optimal dalam melaksanakan fungsi ekologis.

2. Upaya peningkatan kualitas RTH publik untuk mengoptimalkan fungsi ekologis harus disinergikan dengan program lain seperti pengembangan biopori, pengelolan, saluran dan sungai, pengelolaan sampah dan pengelolaan RTH privat secara baik.

3. Hasil analisis dengan unit satuan jumlah dan luas lahan memiliki difisiasi hasil yang sangat signifikan. Hal tersebut menunjukkan bahwa luas RTH merupakan variabel yang sangat penting dalam capaian pengambangan $\mathrm{RTH}$.

4. Setiap stakeholders harus menyadari arti pentingnya perencanaan ruang dan lahan dengan penyediaan RTH yang optimal, sehingga perkembangan ruang terbangun dapat berjalan serasi, selaras, dan seimbang.

Kajian ini masih sebatas dilakukan pada RTH makam dan taman, sehingga perlu dilakukan kajian pada tipe RTH lain. Fungsi sosial dan ekonomi RTH belum manjadi bagian dari kajian ini, sehingga dibutuhkan penelitian lebih lanjut pada fungsi tersebut. Pengembangan RTH merupakan program yang dilakukan di seluruh kota di Indonesia, sehingga kajian dalam lingkup wilayah lain juga diperlukan agar komitmen pembangunan berkelanjutan dapat terwujud.

\section{Daftar Pustaka}

Anonim, Undang-undang. No 26 tahun 2007 tentang Penataan Ruang, Pemerintah Republik Indonesia.

Anonim, Permen PU Nomor 5/PRT/M/2008 tentang Pedoman Penyediaan dan Pemanfaatan Ruang Terbuka Hijau di Kawasan Perkotaan, Kementerian Pekerjaan Umum RI.

Anonim, Peraturan Daerah Kota Surabaya No 7 Tahun 2002 pengelolaan RTH, Pemerintah Kota Surabaya.
Atiqul Haq (2011) Urban Green Spaces and an Integrative Approach to Sustainable Environment, Journal of Environmental Protection, 2011, 2, 601-608, doi:10.4236/jep.2011.25069 Published Online July 2011 (http://www.scirp.org/journal/jep).

Bappeko (2012) Kajian Optimalisasi Pemanfaatan Ruang Terbuka Hijau Publik di Kota Surabaya, Pemerintah Kota Surabaya.

Bilgili. BC and Gökyer. E. (2012). Urban Green Space System Planning, Landscape Planning, Dr. Murat Ozyavuz (Ed.), InTech, ISBN: 978-953-51-06548, pp 107-122.

Barton, S. (2009) Human Benefits of Green Spaces, Sustainable Landscapes Series, University of Delaware.

Silas. J., dkk (2014) Ruang Terbuka Hijau Surabaya; menuju Metropolitan yang Cerdas, Manusiawi dan Ekologis, Badan Perencanaan Pembangunan Kota, Pemerintah Kota Surabaya. 